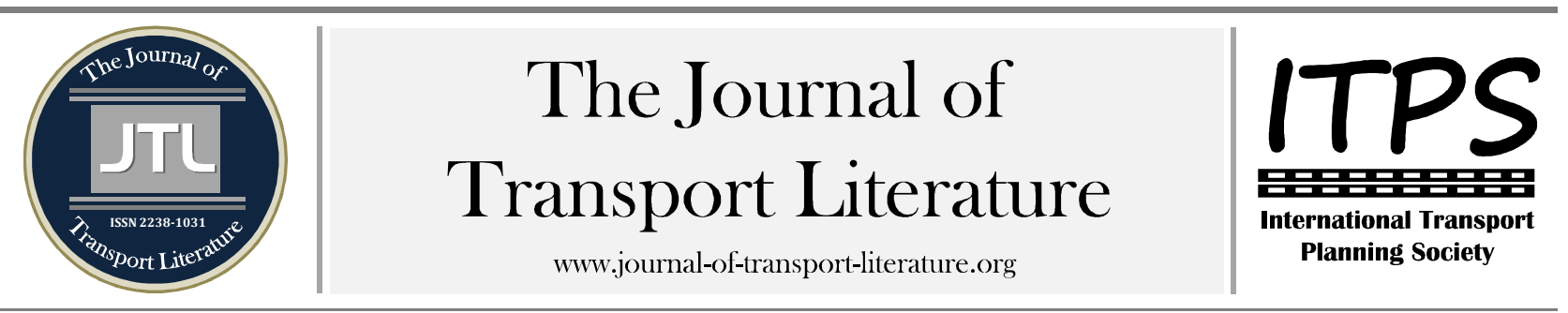

\title{
Airline customer loyalty through analysis of stated preference
}

\author{
Shanna Trichês Lucchesi; Christine Tessele Nodari; Ana Margarita Larrañaga+; Luis Afonso dos Santos Senna \\ Federal University of Rio Grande do Sul, Porto Alegre, Brazil
}

\section{Article Info}

\section{Keywords:}

airline loyalty

switching costs

stated preference

Submitted 17 Oct 2013;

received in revised form 19 Jun 2014;

accepted $28 \mathrm{Jul} 2014$

Licensed under

Creative Commons

CC-BY 3.0 BR.

\begin{abstract}
This study evaluates airline customer loyalty and estimates the switching costs for a domestic airline route in Brazil through a stated preference survey. Several structures of discrete choice models were tested to represent the choice of behavior: multinomial logit, mixed logit random coefficients, multinomial logit incorporating systematic variations of preferences, mixed logit error component and mixed logit error component incorporating systematic variations of preferences. The results showed that loyal passengers are more likely to choose the dominant Brazilian airline Tam. The switching costs of passengers loyal to Tam, for this sample, are equivalent to $15 \%$ of the fare, which represents much more than the percentage for other companies. These passengers are less sensitive to variations in the fares and incur higher costs not to switch airlines.
\end{abstract}

+ Corresponding author. Osvaldo Aranha, 99, 5 andar, Porto Alegre, RS, CEP 90035-190.

E-mail address: analarra@producao.ufrgs.br.

\section{Introduction}

This study evaluates airline customer loyalty and estimates the switching costs for a domestic airline route in Brazil. In order to achieve this goal, the stated preference (SP) of passengers departing from Porto Alegre and arriving in greater São Paulo (Guarulhos, Congonhas and Viracopos airports) were collected.

In a market of repeating purchases, consumers often incur various costs when switching between service providers. These economic and psychological costs that a consumer may face are called switching costs (Klemperer, 1987). Within the airline industry, the switching costs refer to the loss of advantages suffered by passengers switching airlines and may represent a substantial portion of the costs incurred by users. The main effect of the existence of switching costs is the possibility of companies to raise their prices, creating a captive demand.

The literature on switching costs focuses mainly on the behaviors of firms given that customers face switching costs (see e.g. Beggs and Klemperer, 1992; Klemperer, 1987). This studies show that the presence of a switching cost can affect the market power of the firms and consequently result in welfare losses. In addition the switching cost itself is a welfare reducing cost when the customer has to change firm or product. There are relatively few empirical estimates of the size and the determinants of switching costs. One reason for the lack of empirical studies is the difficulties in estimating switching costs (Carlsson et al, 2006).

The costs are seldom of direct monetary expense; instead they are often costs such as learning and transaction costs, and for most customers these costs are not realized since they do not switch (Carlsson et al, 2006). While much of this cost can be attributed to differences in perceived quality, frequent flyer programs contribute to a non-negligible share. Since their rise in the early 1980s, airline frequent flyer programs have been converted into one of the loyalty programs with the highest share in the economy (Basso et al, 2012). However, these costs have been relatively little explored. Some authors who have analyzed its effects are Hartmann and Viard (2008) and Lederman (2007), who focused on the potential switching costs that frequent flyer programs would incur. An alternative analysis was performed by Basso et al. (2009), highlighting that in many cases it is not the passenger who pays the fare, but a third party payer, as is the case with business travelers. The authors consider that a user does not always look for the minimum price, but the highest personal utility, wherein frequent flyer programs have a key role. The economic rewards of accumulating miles can be understood as an incentive or award that the airlines give to users who choose higher priced fares.

This work is within the concept above. The contribution of this work is based mainly on two aspects: (i) on the disaggregated approach used. The studies mentioned above determine the switching costs based on a methodology proposed by Shy (2002), in which the only data required are prices and market share. In this paper, discrete choice models from SP data were estimated., which allowed the inclusion of heterogeneity in the preferences of individuals (random and systematic variations) and the correlation between the sampled individuals; (ii) on the inclusion of variables which characterize passenger loyalty to the airline and the existence of a third party payer. Thus, it was possible to identify customer segments as well as to analyze the heterogeneity of the impact of switching costs within the different segments.

This paper is divided into three sections. Section 1 presents the procedure for data collection, Section 2 the estimation of the models and Section 3 the models' results and analyses of market share. The paper ends with the conclusions. 


\section{Setting and data collection}

This study considers customers' view of the route between São Paulo and Porto Alegre. This route is operated by five different companies: (i) Tam (ii) Gol (iii) Azul, (iv) Avianca, and (v) Pantanal. The first three operate more than $80 \%$ of the flights of this route under study and have significant national market share ANAC (2013), so these three were considered in this study. The surveyed data correspond to choices stated by clients of connecting flights between Porto Alegre and São Paulo. The interviews were carried out face-to-face at the boarding gate of Salgado Filho airport in Porto Alegre, in May, 2013. A random sample of 258 passengers, waiting for boarding or arriving, was collected.

We used stated preference techniques (SP) for the data collection, which use experimental designs to construct hypothetical alternatives proposed to the respondents (Ortúzar and Willumsen, 2011; Hensher, 1994). An advantage of SP techniques is the possibility of determining the importance of factors which are difficult to measure, as airline loyalty.

The survey was based on a full factorial design (Kocur et al., 1982), considering price as an attribute in the choice of an airline, presented in 3 levels. We defined the choices of scenarios in order to avoid any bias in the responses, creating hypothetical but realistic situations, developing a set of scenarios for different fare values.

The study comprised a total of 10 choice scenarios. Each scenario provided the respondent with different fare values associated with the three different companies operating the route Porto Alegre - São Paulo, as equally done in Nodari (1996). On each card, two companies have a base value, while the value of the third one differs. In order to analyze the sensitivity to price changes, three sets of cards with low variations ( $\sigma b=R \$ 10.00)$, mean changes $(\sigma b=R \$ 30.00)$ and high variations $(\sigma b=R \$ 70.00)$ were made. Figure 1 shows the price levels of each card

\begin{tabular}{ccccccccccc}
\hline & Card 1 & Card 2 & Card 3 & Card 4 & Card 5 & Card 6 & Card 7 & Card 8 & Card 9 & Card 10 \\
\hline Tam & BASE & BASE & BASE & BASE & BASE & BASE & $-2 \sigma$ & $-1 \sigma$ & $+1 \sigma$ & BASE \\
Gol & BASE & BASE & BASE & $-2 \sigma$ & $-1 \sigma$ & $+1 \sigma$ & BASE & BASE & BASE & BASE \\
Azul & $-2 \sigma$ & $-1 \sigma$ & $+1 \sigma$ & BASE & BASE & BASE & BASE & BASE & BASE & BASE
\end{tabular}

Figure 1 - Design of the price levels in the survey cards

The base values were defined through a fare survey. Additionally, a questionnaire was applied, containing information about the individuals surveyed. Respondents were asked about the frequency of travel, the most frequent reasons for travel, who paid for the ticket (the passenger himself or a third party) and airline loyalty.

\section{Estimation of discrete choice models}

Discrete choice models based on the random utility theory were used to determine the effect of customer loyalty on the choice of an airline. The multinomial logit (MNL) (McFadden, 1974) is one of the simplest models of discrete choice and also the most used. It is based on the assumption that the random term of the utility function is identically and independently distributed according to a Gumbel distribution. This assumption for the distribution of residuals is rather simplistic, once they depend on the hypothesis of independence and homoscedasticity of the residues (Ben-Akiva et al, 2003). A series of models with more flexible structures has been proposed to allow the estimation of models with correlation between alternatives and structures, variations of MNL, as Hierarchical logit models (Williams, 1977) and cross-nested logit (Vovsha, 1997). The traditional way to capture heterogeneity of preferences in discrete choice models has been the inclusion of systematic variations of preferences (Train, 2009; Ortúzar and Willumsen, 2011). However, there are factors influencing preferences that are unobservable or difficult to measure. In recent years, the use of mixed logit - ML (Brownstone and Train, 1999), has been increasing, allowing the incorporation of variations in unobservable preferences. These models imply an independently and identically distributed random term according to a Gumbel distribution - as well as the MNL -, but with an additional random component, which permits to work with greater flexibility. Depending on the assumptions considered on the various random terms it is possible to model correlation and heteroscedasticity (Brownstone and Train, 1999). In order to characterize the heterogeneity of individuals more accurately, Bhat (1998) proposed an approach that allows the consideration of the existence of heterogeneity, both systematic and random. Thus, mixed models with systematic variation preferences began to be studied.

In this work various structures of discrete choice models were tested in order to verify changes in the tastes of the individuals that make up the sample, better agreement of the model to the data collected and seeking to represent the most appropriate choice behavior. In all structures linear utility functions were used in the parameters, the usual practice in modelling transport demand (Ben-Akiva and Lerman, 1995, Silva et al, 2014, Murca et al, 2013). The model structures tested that showed better agreement with data were: (i) multinomial logit, (ii) multinomial logit with random coefficients, (iii) multinomial logit incorporating systematic variation of preferences, (iv) mixed logit with the error component case, and (v) mixed logit error component incorporating systematic variations of preferences. These models are described below.

Initially simpler structures were tested, which estimated MNL models. The MNL considers the estimated parameters for the various fixed variables, which are the same for all individuals. Changes in the tastes and preferences of individuals may influence the choice of airline. These variations have been represented in models in two ways: (i) by assuming that preferences are randomly distributed in the population, and (ii) by incorporating systematic variations of preferences. In the first case, mixed logit random coefficients models (LRC) were estimated. The LRC models allow the coefficients of the attributes of the alternatives to vary within the population, following a given probability distribution. Assuming the distribution is known (e.g., normal, log normal, triangular), the model returns the estimators of the parameters that define this distribution, such as mean and variance. Three distributions were tested to specify a random coefficient model (normal, $\log$ normal and triangular). The normal distribution presented better goodness of fit than the others (Table 1 next section).

Subsequently, multinomial logit models were estimated incorporating systematic variations in relation to the passenger's airline loyalty and in relation to ticket paid by the passenger or third parties. The inclusion of these systematic variations allowed the study of the effect of variations in the fare within the different categories of passengers defined (loyal and non-loyal; who paid for the ticket). Binary variables were used to categorize individuals in the sample.

The responses of the same individual to a stated preference survey may be correlated, which is called Panel Effect. MNL models and LRC do not represent this effect, so it is necessary to include an additional term that represents the panel effect. 
Thus, mixed logit error component (EC) models have been estimated to represent this effect. Variations of the preferences of individuals were added to the EC models. Terms were included in the utility function to represent the correlation between responses from the same individual (panel effect) and heterogeneity among individuals (systematic variations of preferences).

In order to control endogeneity we used a standard SP experiment (instead of a pivoting procedure), where the alternatives are constructed without regard to the respondent's choice in the RP setting (Train and Wilson, 2008). The classical form of endogeneity arises in random utility models if variables that enter systematic utility components are correlated with random utility components, such as some relevant product attributes might be omitted in product characterizations (Louviere et al, 2005). In stated preference settings researchers have designed choice sets that individuals face on given choice occasions and omitted variables are supposed to be equal in all the experiments. This tends to eliminate the presence of endogeneity.

\section{Analysis of results}

The responses of the survey showed that the most common reason for traveling is tourism (47\%) followed by business (35\%). Most respondents (61\%) paid for their own ticket. Some of them do not always travel with the same airline (42\%). In case of tickets paid by the company (26\% of respondents), the predominance of non-loyal passengers (22\%) is also noted. Regarding the frequency of travel, $71 \%$ travel less than once a month, while $19 \%$ travel from 1 to 3 times a month and $10 \%$ travel more than 3 times a month. Table 1 summarizes the results of estimating the models of airline choice.

Table 1 - Results of the models of airline choice

\begin{tabular}{|c|c|c|c|c|c|c|c|c|c|c|c|c|c|c|}
\hline \multirow{2}{*}{ Variable } & \multicolumn{2}{|c|}{ MNL (1) } & \multicolumn{2}{|c|}{ LRC } & \multicolumn{2}{|c|}{ MNL (2) } & \multicolumn{2}{|c|}{ MNL (3) } & \multicolumn{2}{|c|}{$\operatorname{EC}(1)$} & \multicolumn{2}{|c|}{$\mathrm{EC}(2)$} & \multicolumn{2}{|c|}{$\operatorname{EC}(3)$} \\
\hline & Coef. & Stat-t & Coef. & Stat-t & Coef. & Stat-t & Coef. & Stat-t & Coef. & Stat-t & Coef. & Stat-t & Coef. & Stat-t \\
\hline \multicolumn{15}{|l|}{ Fare } \\
\hline Fare_A & $-0,038$ & $-20,97$ & $-0,038$ & $-18,01$ & $-0,039$ & $-21,32$ & $-0,038$ & $-20,96$ & $-0,092$ & $-19,4$ & $-0,094$ & $-20,11$ & $-0,093$ & $-20,37$ \\
\hline Fare_G & $-0,04$ & $-21,34$ & $-0,04$ & $-14,5$ & $-0,042$ & $-21,97$ & $-0,04$ & $-21,32$ & $-0,093$ & $-19,9$ & $-0,098$ & $-20,11$ & $-0,093$ & $-20,89$ \\
\hline Fare_T & $-0,035$ & $-19,5$ & $-0,036$ & $-18,17$ & $-0,038$ & $-20,73$ & $-0,037$ & $-19,66$ & $-0,085$ & $-16,89$ & $-0,093$ & $-19,36$ & $-0,091$ & $-17,97$ \\
\hline \multicolumn{15}{|l|}{ Airline loyalty } \\
\hline Loya_G $(-1,0)$ & 0,287 & 2,22 & 0,287 & 2,22 & - & - & 0,287 & 2,21 & 0,796 & 1,65 & - & - & 0,789 & 1,65 \\
\hline Loya_T $(1,0)$ & 0,739 & 6,79 & 0,697 & 6,44 & - & - & 0,734 & 6,75 & 1,98 & 3,25 & - & - & 1,98 & 3,36 \\
\hline \multicolumn{15}{|c|}{ Payment (third payer or passanger) } \\
\hline Pay. T $(1,0)$ & 0,451 & 4,47 & 0,462 & 4,52 & 0,435 & 4,3 & - & - & 1,3 & 2,45 & 1,18 & 2,47 & - & - \\
\hline \multicolumn{15}{|l|}{ Trip frequency } \\
\hline Freq. $G(-1,0)$ & $-0,48$ & $-3,58$ & $-0,509$ & $-3,72$ & $-0,486$ & $-3,59$ & $-0,481$ & $-3,57$ & $-1,47$ & $-2,49$ & $-1,72$ & $-2,87$ & $-1,48$ & $-2,5$ \\
\hline Freq. $\mathrm{T}(1,0)$ & $-0,392$ & $-3,11$ & $-0,388$ & $-3,08$ & $-0,387$ & $-3,04$ & $-0,414$ & $-3,34$ & $-0,972$ & $-1,6$ & $-1,3$ & $-2,01$ & $-0,943$ & $-1,4$ \\
\hline \multicolumn{15}{|l|}{ Interaction } \\
\hline LG *FG & - & - & - & - & 0,006 & 4,55 & - & - & - & - & 0,021 & 4,66 & - & - \\
\hline $\mathrm{LT} * \mathrm{FT}$ & - & - & - & - & 0,008 & 8,66 & - & - & - & - & 0,028 & 6,17 & - & - \\
\hline $\mathrm{PT} * \mathrm{FT}$ & - & - & - & - & - & - & 0,003 & 4,42 & - & - & - & - & 0,01 & 2,63 \\
\hline Constant $\mathrm{T}$ & $-0,276$ & $-1,65$ & $-0,195$ & $-1,6$ & $-0,085$ & $-1,56$ & 0,01 & 1,6 & $-0,634$ & $-1,6$ & - & - & - & - \\
\hline Sigma painel & - & - & - & - & - & - & - & - & 2,89 & 15,93 & 2,88 & 15,94 & 2,89 & 16,02 \\
\hline Sigma.Fare_A & - & - & 0,001 & 1,7 & - & - & - & - & - & - & - & - & - & - \\
\hline Sigma.Fare_G & - & - & $-0,002$ & $-0,56$ & - & - & - & - & - & - & - & - & - & - \\
\hline \multirow[t]{2}{*}{ Sigma.Fare_T } & - & - & 0 & 0,44 & - & - & - & - & - & - & - & - & - & - \\
\hline & \multicolumn{2}{|c|}{$\begin{array}{c}* \mathrm{~L}(\log )=- \\
2124,11 \\
\text { Pseudo- } \mathrm{R}^{2}= \\
0,251\end{array}$} & \multicolumn{2}{|c|}{$\begin{array}{c}\mathrm{L}(\log )=- \\
2124,13 \\
\text { Pseudo- } \mathrm{R}^{2}= \\
0,251\end{array}$} & \multicolumn{2}{|c|}{$\begin{array}{c}* \mathrm{~L}(\log )=- \\
2106,201 \\
\text { Pseudo- } \mathrm{R}^{2}= \\
0,250\end{array}$} & \multicolumn{2}{|c|}{$\begin{array}{c}* \mathrm{~L}(\log )=- \\
2124,509 \\
\text { Pseudo- } \mathrm{R}^{2}= \\
0,250\end{array}$} & \multicolumn{2}{|c|}{$\begin{array}{c}\mathrm{L}(\log )=-- \\
1445,63 \\
\text { Pseudo- } \mathrm{R}^{2}= \\
0,490\end{array}$} & \multicolumn{2}{|c|}{$\begin{array}{c}* \mathrm{~L}(\log )=- \\
1430,70 \\
\text { Pseudo- } \mathrm{R}^{2}= \\
0,495\end{array}$} & \multicolumn{2}{|c|}{$* \mathrm{~L}(\log )=-1445,23$} \\
\hline
\end{tabular}

$* \mathrm{~L}(\log )=$ Likelihood $(\log ) \quad \mathrm{G}=\mathrm{Gol} \quad \mathrm{T}=\mathrm{Tam} \quad \mathrm{A}=$ Azul $\quad$ L=Loyalty $\quad \mathrm{F}=$ Fare $\quad \mathrm{P}=$ Pay

MNL(1):multinomial logit; LRC:logit random coefficients; MNL (2):multinomial logit with systematic variation preferences in relation to the passenger's airline loyalty; MNL (3):multinomial logit with systematic variation preferences in relation to who paid the ticket- passenger or third parties -; EC (1):mixed logit error component with panel effect; EC (2) mixed logit error component with panel effect and systematic variation preferences in relation to the passenger's airline loyalty and EC (3):mixed logit error component with panel effect and systematic variation preferences in relation to who paid the ticket

The adjustment of the first four models (Table 1), MNL, LRC, MNL (2) and MNL (3), is similar (Pseudo-R2 = 0.25). The variance estimators that define the distribution in LRC model were not significant, indicating homogeneity in the preferences of the individuals. The likelihood ratio test with 5\% significance reveals that the addition of the error component in mixed models (panel effect) to the MNL model has a significant impact. They show better agreement with the data than previous models (Pseudo-R2 $=0.49$ and 0.495 ). Specific coefficients for companies Tam and Gol were used assuming that the effect of loyalty, frequency of travel and who paid for the ticket can affect all the alternatives differently.

\subsection{Fare effect}

The parameters relating to the fare had the expected negative sign in all estimated models, given that any increase in fare decreases the probability of choosing a particular airline. The values of these parameters allow us to state that passengers sampled are more sensitive to price changes of Gol and Azul airlines than to changes in the price of Tam fares.

\subsection{Airline loyalty effect}


The estimated models show that passengers traveling with the same company are more likely to choose Gol and Tam airlines than Azul. Furthermore, the estimated coefficients for the variables Loya_Tam and Loya_Gol also show us that the preference for Tam is significantly higher than that of Gol. This result may be due to the user's higher valuation towards Tam attributes in relation to other airlines. Factors such as perceived quality, service, and advantages offered by the company and frequent flyer programs were not included explicitly in the representative utility function. These factors may influence the preference for Tam with individuals sampled. So as to better study this effect, it is necessary to analyze the interaction effect shown below.

The inclusion of systematic variations of preferences regarding loyalty, presented in MNL (2) and EC(2) models, showed interesting results. The MNL model (2) incorporates a binary variable that represents the airline loyal traveler interacting with the fare variable. The EC model (2) incorporates this interaction and also the panel effect. In both models the interaction of these variables was significantly different from zero. The positive coefficient shows that companies with loyal passengers are less sensitive to fare variations. The frequent flyer plans probably have an important effect on this result. The economic rewards of earning miles with the same company can be compensated with the fare difference. The biggest impact of this interaction is observed with Tam. Studies by Lederman (2007) and Hartamann and Viard (2008) analyzed the effect of frequent flyer plans and user loyalty, verifying the economic losses that users would have if switched airlines.

\subsection{Effect of the existence of a third payer}

The results of all models show that when the ticket is paid by the passenger the probability of choosing Tam instead of Azul or Gol decreases. This can occur because their fares are in general higher than other companies'. The inclusion of systematic variations of preferences in relation to the payment of the ticket was presented in MNL models (3) and EC (3). The MNL model (3) incorporates a dummy variable representing the ticket paid by third parties (a company, according to most respondents) interacting with the fare variable. The variable Pay_Tam represents the business traveler, in which case the ticket is usually paid by the company. The EC model (3) incorporates the effect panel in addition to this interaction. The interaction of these variables was significant in both models, with a positive coefficient. Passengers who pay for their own ticket are more sensitive to fare variations. Thus, it is possible to verify the impact of a third party paying for the ticket. This result coincides with those found in other studies. Several authors found that business travelers tend to value travel time more than ticket fare (Alves and Strambi, 2011; Tsamboulas and Nikoleris, 2008.). Basso et al. (2009) observed that passengers who do not pay the fare do not always look for the minimum price but the alternative that promotes greater individual utility.

\subsection{Effect of trip frequency}

The parameters related to the frequency of travel showed a negative sign in all the models estimated which indicates that frequent passengers have less probability than not frequent passengers of choosing the Tam and Gol alternative (Azul alternative was normalized to zero). Frequent passengers are more likely to choose Azul rather than other companies. Passengers flying more often have different perceptions about the service offered. The results favoring Azul may be due to the fact, for example, that aircraft operated by the company have more room between seats (ANAC, 2013). It is imperceptible to passengers who do not fly often in a month, but it is uncomfortable when there is a regular need.

\subsection{Market share and switching costs}

From the discrete choice models estimated it is possible to estimate the market share of each company and determine switching costs. By selecting the EC model (2), which showed better agreement with the data, the market shares of the three companies in different fare scenarios were estimated. These estimates were calculated by the method of enumeration sample, using the Biogeme software (Bierlaire, 2008). Figure 2 shows the probability of choice as the fare changes, to interviewees who are both loyal and non-loyal to Tam.
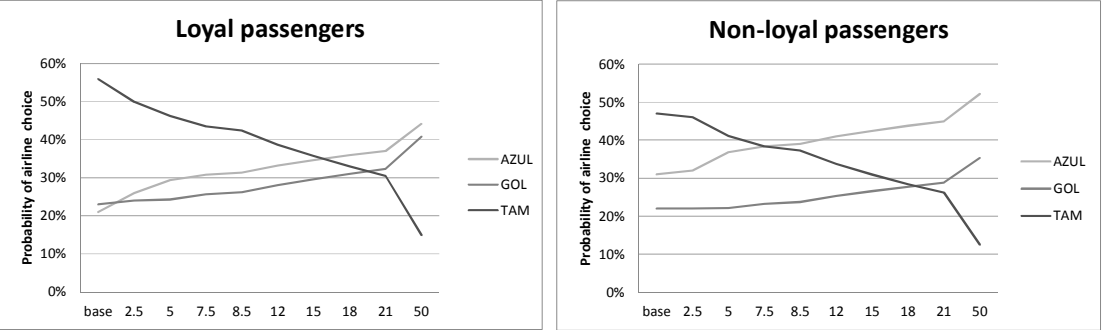

Figure 2 - Probability of airline choice for Tam fare variation a) for non-loyal passengers b) for loyal passengers

It is possible to notice that any increases in Tam fares - represented by the light grey line in the figure - decrease the probability of choosing this company. Tam loyal passengers are willing to incur greater costs not to switch companies than non-loyal ones. The switching costs for loyal passengers $5 \%$ of the ticket fare. From this percentage onwards, loyal passengers will switch to Azul, but only would for Gol if the fare suffered an increase of $21 \%$.

Similar analyses were performed for Azul fare variations. The results showed that Azul loyal passengers are not willing to incur switching costs to stay with the company. This result is expected by observing Figure 2.a. It is also possible to observe that the largest initial share in the base scenario is Gol's (23\%) compared to Azul (21\%) for loyal passengers. Thus, it is expected that any increases in Azul fares (keeping the other airline fares constant), decrease the probability of choosing this company even further. Therefore, for loyal passengers the probability of choosing Azul would always remain smaller than other airlines, with no switching point from Azul to another company.

\section{Conclusion}

This study evaluated airline loyalty, estimating the switching costs for companies Gol, Azul and Tam with passengers traveling between Porto Alegre and São Paulo. Several model structures were tested, showing similarity in their effects on the explanatory variables. Among the estimated models, the mixed logit model of error component incorporating systematic 
variations of preferences - called EC (2) - showed better agreement with data. This model incorporates the interaction between the loyal traveler and the fare variable, as well as the panel effect.

The estimated models show that passengers traveling with the same company are more likely to choose Gol and Tam airlines than Azul. The preference for Tam is significantly higher than that of Gol. The inclusion of systematic variations of preferences regarding loyalty showed that companies with loyal passengers are less sensitive to fare variations.

This last result remains when fare varies. Passengers loyal to Tam are willing to incur higher costs than non-loyal ones, so as not to switch companies. The costs for switching airlines for loyal passengers reach the value of $15 \%$ of the value of the ticket. From this percentage on loyal passengers will switch Azul, but would switch to Gol if the fare suffered an increase of $21 \%$. This result shows that users do not always seek the minimum price, but the highest personal utility.

The frequent flyer programs probably have an important effect. The economic rewards of earning miles with the same company can be compensated by the fare difference. Also, the difference between the aircraft of the companies can influence this outcome and factors such as quality and service also probably influence the result.

The results allowed the verification of the impact of a third party paying for the ticket. Passengers who pay for their own ticket are more sensitive to fare variations. Future researches in different routes can characterize passengers regionally, highlighting their behavior and the influence of loyalty for different points throughout the country. Additionally explanatory variables could also be included, such as identifying the influence of snacks, of delays, of the presentation of the crew, security, among others, when choosing an airline. This technique can be used for the investigation of possible deficits in providing the service that may be corrected, causing user migration and thus elevating the market share of the company in market.

\section{Acknowledgements}

We thank the press offices of Azul and Tam airlines and Gol Memory Center for allowing the use of their names in this survey and thank the editor and referees for the comments to improve the paper.

\section{References}

Alves, B., \& Strambi, O. (2011) Variação sistemática da preferência em modelos de escolha de modo no acesso terrestre a aeroportos considerando a confiabilidade do tempo de viagem. Transporte em Transformação XV. Brasília: Ed. Positiva.

ANAC -Imprensa da Agência Nacional de Aviação Civil (2013). Available in www.anac.gov.br.

Basso, L., Clements. M., \& Ross, T. (2009) Moral hazard and customer loyalty programs. American Economic Journal: Microeconomics, 1(1), 101-123.

Basso, L., \& Feres, F. (2012) Programa de viajero frecuente bajo selección adversa y riesgo moral. XVII Congreso Panamericano de Ingeniería de Tránsito,Transporte y Logística. Santiago.

Bhat, C. R. (1998) Accomodating flexible subtitution patterns is multidimensional choice modeling: formulation and application to travel mode and departure time choice. Transportation Research Part B., 32(7), 344-466.

Beggs, A., \& Klemperer, P. (1992). Multiperiod competition with switching costs. Econometrica., 60(3), 651-666.

Ben-Akiva, M., Bolduc, D., \& Walker, J. (2003) Specification, identification, and estimation of the logit kernel (or continuous mixed logit) model. 5th Invitational Choice Symposium, Asilomar.

Ben-Akiva, M., \& Lerman, S. R. (1985) Discrete choice analysis: Theory and applications to travel demand. Cambridge. MIT Press.

Bierlaire, M. (2003) BIOGEME: A free package for the estimation of discrete choice models, 3rd Swiss Transportation Research Conference, Ascona.

Brownstone, D., \& Train, K. (1999) Forecasting new product penetration with flexible substitution patterns. J. Econometrics, 89, $109-129$.

Carlsson, F., \& Lofgren, A. (2006) Airline choice, switching costs and frequent flyer programs. Taylor \& Francis Journals, 38(13), 14691475.

Hartmann, W., \& Viard, B. (2008) Do frequency reward programs create switching cost? A dynamic structural analysis of demand in a reward program. Quantitative Marketing and Economics, 6(2), 109-137.

Hensher, D. A. (1994) Stated preference analysis of travel choices: The state of practice. Transportation, 21(2), 107-133.

Lederman, M. (2007) Do enhancements to loyalty programs affect demand? The impact of international frequent-fliers partnership on domestic airline demand. RAND Journal of Economics, 38(4), 1134-1158.

Louviere, J. J., Hensher, D. A. \& Swait, J. D. (2000) Stated choice methods. United Kingdom: Cambridge University Press.

Louviere, J., Train, K., Ben-Akiva, M., Bhat, C., Brownstone, D., Cameron, T., Carson, C., Deshazo, J., Fiebig, D., Greene, W., Hensher, D. \& Waldman, D. (2005). Recent progress on endogeneity in choice modeling. Marketing Letters, 16(3-4), 255-265.

Klemperer, P. (1987) Markets with consumer switching costs. The quarterly journal of economics, 102(2), 375-394.

Kocur, G. T, Adler, T., Hyman, W. \& Aunet, B. (1982). Guide to forecasting travel demand with direct utility assessment. Washington DC: Urban Mass Transportation Administration.

McFadden, D. (1974) Conditional logit analysis of qualitative choice behavior. Frontiers in Econometrics. New York: Academic Press.

McFadden, D., \& Domenic, T. (1972) A disaggregated Behavioral Model of Urban Travel Demand. Massachusetts: Charles River Associates, Inc. Cambridge.

Murça, M. C. R., \& Correia, A. R. (2013). Análise da modelagem da escolha aeroportuária em regiões de múltiplos aeroportos. Journal of Transport Literature, 7(4), 130-146.

Nodari, C. T. (1996) Influência de preço e marca na demanda por transporte aéreo. Dissertação (Mestrado em Engenharia de Produção), Universidade Federal do Rio Grande do Sul, Porto Alegre.

Ortúzar, J. D., \& Willumsen, L. G. (2001) Modelling transport. Chichester: John Wiley \& Sons.

Silva, F. G. F., \& De Souza, S. A. (2014) Estimando valor de tempo de viagem com diferentes fontes de dados utilizando modelos logit. Journal of Transport Literature, 7(4), 107-129.

Shy, 0. (2002) A quick-and-easy method for estimating switching costs,International Journal of Industry Organization, 20 (1), 71-87.

Train, K. (2009) Discrete choice methods with simulation, Cambridge: Cambridge University Press.

Train, K., \& Wilson, W. (2008) Estimation on stated-preference experiments constructed from revealed-preference choice. Transportation Research Part B: Methodological, 42(3), 191-203.

Vovsha, P. (1997) Cross nested logit model: an application to mode choice in the Tel-Aviv metropolitan area. Transportation Research Board - 76th Annual meeting, Washington D.C.

Williams, H. C. W. L. (1997) On the formation of travel demand models and economic evaluation measures of user benefit. Environment and Planning A, 9(3), 285-344. 